\title{
Viral Load Suppression after Enhanced Adherence Counseling and Its Predictors among High Viral Load HIV Seropositive People in North Wollo Zone Public Hospitals, Northeast Ethiopia, 2019: Retrospective Cohort Study
}

\author{
Gedefaw Diress $\mathbb{D}^{1}$, Samuel Dagne $\mathbb{D}^{\mathrm{D}},{ }^{2}$ Birhan Alemnew ${ }^{\mathbb{D}}$, ${ }^{1}$ Seteamlak Adane, \\ and Amanuel Addisu ${ }^{1}$ \\ ${ }^{1}$ College of Health Sciences, Woldia University, Woldia, Ethiopia \\ ${ }^{2}$ College of Medicine and Health Science, Bahir Dar University, Bahir Dar, Ethiopia
}

Correspondence should be addressed to Gedefaw Diress; gedefawdiress@gmail.com

Received 10 December 2019; Revised 19 February 2020; Accepted 19 March 2020; Published 21 April 2020

Academic Editor: Bhaskaran Unnikrishnan

Copyright (c) 2020 Gedefaw Diress et al. This is an open access article distributed under the Creative Commons Attribution License, which permits unrestricted use, distribution, and reproduction in any medium, provided the original work is properly cited.

\begin{abstract}
Background. The World Health Organization currently encourages enhanced adherence counseling for human immunodeficiency virus (HIV) seropositive people with a high viral load count before a treatment switch to the second-line regimen, yet little is known about viral load suppression after the outcome of enhanced adherence counseling. Therefore, this study aimed to assess viral suppression after enhanced adherence counseling sessions and its predictors among high viral load HIV seropositive people. Methods. Institutional-based retrospective cohort study was conducted among 235 randomly selected HIV seropositive people who were on ART and had a high viral load (>1000 copies/ml) from June 2016 to January 2019. The proportion of viral load suppression after enhanced adherence counseling was determined. Time to completion of counseling sessions and time to second viral load tests were estimated by the Kaplan-Meier curve. Log binomial regression was used to identify predictors of viral resuppression after enhanced adherence counseling sessions. Result. The overall viral load suppression after enhanced adherence counseling was $66.4 \%(60.0-72.4)$. The median time to start adherence counseling session after high viral load detected date was 8 weeks (IQR 4-8 weeks), and the median time to complete the counseling session was 13 weeks (IQR 8-25 weeks). The probability of viral load suppression was higher among females (ARR $=1.2,95 \%$ CI: 1.02-1.19) and higher educational status (ARR $=1.7,95 \%$ CI: 1.25-2.16). The probability of viral load suppression was lower among people who had 36-59 months duration on ART $(\mathrm{ARR}=0.35,95 \% \mathrm{CI}: 0.130-0.9491)$ and people who had $>10,000$ baseline viral load count $(\mathrm{ARR}=0.44,95 \% \mathrm{CI}: 0.28-0.71)$. Conclusion. This study showed that viral suppression after enhanced adherence counseling was near to the WHO target (70\%) but highlights gaps in time to enrolment into counseling session, timely completion of counseling session, and repeat viral load testing after completing the session.
\end{abstract}

\section{Introduction}

In the mid-2017, 20.9 million people living with HIV were taking antiretroviral therapy (ART) globally [1] and monitoring of people on ART is crucial to ascertain successful treatment, identify adherence challenges, and determine whether ART regimens should be switched in cases of treatment failure [2]. The World Health Organization
(WHO) recommended the use of viral load testing as the gold standard to monitor the patient's responses to ART [2]. The three 90s (90-90-90) strategy which was developed by UNAIDS clearly states that $90 \%$ of all people on ART should have a suppressed viral load [3].

Initial viral load testing in people with HIV should be after 6 months of initiating ART and every 12 months thereafter routinely. Besides, targeted viral load testing was 
offered for suspected clinical or immunological failure [4]. The result of a viral load test could be unsuppressed (viral load count greater than 1000 copies/ml), which implies that $\mathrm{HIV}$ is not controlled by the current ART regimen. Past evidence showed that viral suppression at the first test is much lower than expected and viral replication continues to be a major challenge among patients living with HIV. $\mathrm{Pa}$ tients who have unsuppressed viral load were found to have an increased risk of clinical progression to acquired immunodeficiency syndrome (AIDS) and mortality when compared with patients with a complete virologic response [5].

Since poor adherence is the most common reason for treatment failure [6-8], the WHO recommends enhanced adherence counseling sessions for 3-6 months for people with high viral load count before diagnosing first-line treatment failure. Enhanced adherence counseling (EAC) is a continual and repeated process that involves a structured assessment of the current level of adherence, explore the specific barriers the patient must overcome, assisting patients to identify solutions, and address barriers and develop an individualized adherence interventional plan which improve viral load suppression and reduces subsequent treatment failure [9].

Performing repeated viral load test is recommended by the WHO for all people with unsuppressed viral load $(>1000$ copies $/ \mathrm{ml}$ ). If the patient complete $3 \mathrm{EAC}$ monthly sessions each one month apart, the client is perfectly adherent for 3-6 months and there is no opportunistic infection during the 3-6 months [10]. Even though the recommended time to complete the three EAC sessions was 90 days, the previous study conducted in Uganda showed that only $37 \%$ of patients complete the sessions in the recommended time interval. About $16 \%$ of patients who enrolled to EAC received only one or two EAC sessions [11], which implies poor handling of patients with unsuppressed viral load. This triggers us to conduct this study for estimation of time of completion of EAC session and time to second viral load test in Ethiopia.

According to the WHO estimation, up to $70 \%$ of patients with initial high viral load count (greater than 1000 copies/ml) achieved virologic suppression after 3-6 enhanced adherence counseling session [10], but only $23 \%$ of patients achieved viral load suppression after enhanced adherence counseling in Uganda [11].

In March 2016, Ethiopia Federal Ministry of Health initiated routine viral load testing for all HIV seropositive people with the goal of all eligible patients receiving at least one viral load test every year [10]. In Ethiopia, a total of 128,615 (54\% of total HIV seropositive people on ART) viral load tests were performed from March 2016 to January 2019. Viral load suppression at the first viral load test was reported in $73 \%$ of pediatric patients and $83.3 \%$ of adult patients. This implies in Ethiopia $27 \%$ of pediatrics and $17 \%$ of adults required enhanced adherence counseling and repeat viral load testing after 3-6 months [12]. In North Wollo Governmental Hospitals, from 6245 currently on ART patients, around 4012 viral load tests were performed between the years 2016 and 2019. High viral load copies (>1000 copies/ $\mathrm{ml})$ at the first test were reported in 568 patients [13].
Furthermore, to our knowledge, no research has been done in Ethiopia which assessed viral load suppression after EAC sessions among high viral load HIV seropositive people who are on ART. And the finding of this research will help Ethiopian Ministry of Health and other stakeholders to assess the progress in the implementation of the national guidelines focus on EAC and to improve the patient's quality of life. Therefore, this study aimed to assess viral load suppression after EAC, estimate time to completion of the EAC session, estimate time to second viral load test, and identify the predictors of viral load suppression among high viral load HIV seropositive people on ART.

\section{Materials and Methods}

2.1. Study Setting. This study was conducted at three public hospitals which provide ART service in North Wollo Zone [14]. All the three hospitals started conducting routine viral load testing for all HIV infected people from June 2016 onwards as per the national guidelines. Those with viral load $>1000$ copies/ml are referred for enrolment in EAC. Enhanced adherence counseling consists of three sessions done on a monthly basis. After three EAC sessions, each client is assessed for adherence and a repeat viral load test is performed. If the viral load is suppressed ( $\leq 1000$ copies $/ \mathrm{ml}$ of blood), the client is continued on the same ART regimen. On the other hand, if the repeat viral load is greater than 1000 copies/ml despite good adherence to therapy, the client is switched to the second-line ART regimen.

2.2. Study Design and Period. An institutional-based retrospective cohort study was conducted from March to May 2019.

\subsection{Population}

2.3.1. Source Population. All HIV infected people on the first-line regimen who had viral loads $>1000$ copies $/ \mathrm{ml}$ after 6 months on ART between June 2016 and January 2019 at three public hospitals of North Wollo Zone.

2.3.2. Study Population. All HIV infected people with viral load greater than 1000 copies/ml at the first test and had at least one repeated viral load result after complete enhanced adherence counseling session in Governmental Hospitals of North Wollo Zone.

\subsection{Eligibility Criteria}

2.4.1. Inclusion Criteria. All HIV infected people with documented viral load results greater than 1000 copies $/ \mathrm{ml}$.

2.4.2. Exclusion Criteria. Clients who had a follow-up of fewer than 6 months, patients who did not start EAC session, and clients who had no second viral load result were excluded. 
2.5. Sample Size Calculation. The required sample size was calculated by Epi-Info version 7 with the following assumption:

(1) $95 \% \mathrm{CI}$

(2) $80 \%$ power

(3) The percentage of outcome (viral suppression) in the exposed group (female) is $10.3 \%$ by selecting sex (a variable which result in large sample size) as exposure variable from a study performed in Uganda.

The calculated sample size was 213 . By adding $10 \%$ for incomplete data, the final sample size reached 235.

2.6. Sampling Procedure. All three public hospitals were included in the study, and the total sample size was allocated proportionally among each hospital based on the number of patients with a viral load count of greater than 1000 copies/ $\mathrm{ml}$. The study participants were selected through simple random sampling technique from a viral load registration book.

2.7. Data Collection Tools and Procedure. Data were collected from patient's chart, enhanced adherence counseling sheet, viral load registration book, and laboratory request using a pretested structured checklist. Accordingly, all charts containing detailed information about patients who were on ART were reviewed. When there were incomplete data, the data collectors have tried to get from different data sources (patient's chart and follow-up form). If clinical parameters and laboratory results (CD4 count and WHO clinical stage) were not found at the start of enhanced adherence counseling sessions, the data which were most recent to the starting date of enhanced adherence counseling sessions were considered as baseline data. Six BSc degree nurse as data collectors and three ART data managers as supervisor were participated in the data collection process.

2.8. Variables. The main outcome of interest was viral suppression (suppressed/unsuppressed). Explanatory variables were age, the current ART regimen, viral load count at the start of EAC session, sex, WHO clinical stage, baseline CD4 count, nutritional status, residence, opportunistic infections (OIs), functional status, isoniazid preventive therapy status, cotrimoxazole preventive therapy (CPT) status, duration on ART (determined using date of ART initiation and date of ART clinic visit), and level of ART adherence. Baseline means at the time of high viral load determination (recent to the study). Opportunistic infection is infections that occur more frequently or more severe in people with HIV than in people with healthy immune systems, and it is used as criteria for the WHO clinical staging.

2.9. Measurements. Viral load was determined through realtime polymerase chain reaction (PCR) assay. Viral load after EAC was classified as suppressed or unsuppressed based on 2018 Ethiopian national guidelines for comprehensive HIV prevention, care, and treatment. Viral load suppression is considered when viral load is less than or equal to 1000 copies $/ \mathrm{ml}$ after EAC, and high viral load is defined when a client is found to have a viral load of $>1000$ copies $/ \mathrm{ml}$ on a routine or need-based viral load test. Level of ART adherence was classified as good/fair/poor based on the percentage of ARV drug taken (good ART adherence defined as $95 \%$ or greater of doses taken as prescribed, fair adherence defined as $85-94 \%$ of doses taken as prescribed, and poor adherence defined as less than $85 \%$ of doses taken as prescribed) [15].

2.10. Data Quality Management. Data quality was assured through designing a proper data collection material. Two days long training was given for both data collectors and supervisors on the objective of the study, data extraction, and recording from patient's chart and registration books. During the data collection period, a supervisor was assigned to make sure that there were no missed data. The overall activities were controlled by the principal investigator of the study. By taking $10 \%$ of participants randomly from Dessie Referral Hospital, pretest was performed to assess the reliability and consistency of the data collection tool. The data were entered by double entry, and at the end of data entry, data cleaning was carried out using frequency, cross tabulation, sorting, and listing to check missed value and outliers.

2.11. Data Analysis Procedure. Data were entered into Epi data version 3.1 and analyzed using Stata version 14 . Descriptive statistics, including mean and frequencies, were used to describe characteristics of the study participants. Viral load suppression after EAC sessions was presented as proportion. Time to completion of EAC session and time to second viral load test was presented by the Kaplan-Meier curve (survival function). Log binomial regression model was used to identify predictors of viral load suppression. We preferred log binomial regression over logistic regression model in this study to report adjusted risk ratio because the incidence of outcome was greater than $10 \%$.

2.12. Ethical Consideration. Ethical clearance was obtained from the Institutional Review Committee of Woldia University. Since it was a retrospective analysis of the identified data, a waiver of consent was obtained. Even though most of the data were collected from the patient chart and follow-up card, a written patient consent form without any personal identifiers was prepared. The recorded data were not accessed by a third person except by the investigators in order to kept confidentiality.

\section{Result}

3.1. Baseline Characteristics of Study Participants. A total of 235 participants were included in the study, of whom 121 $(51.5 \%)$ were female. The mean age of study participants was $33.1( \pm 12.49 \mathrm{SD})$. Majority $(109(46.4 \%))$ of participants were 
married, and around $36 \%$ of participants have completed the primary educational level. At baseline, most of the participants were staged in WHO clinical stage $1(90.6 \%)$, had a CD4 count above or equal to 500 cells/ $\mu \mathrm{l}$ (42.3\%), and $83 \%$ of participants had good ART adherence level at the start of EAC sessions. From all participants, 105(44.7\%) had a viral load count between 1,000 and 5,000 copies/ $\mathrm{ml}$ when enrolled to EAC sessions (Table 1).

\subsection{Proportion of Viral Load Suppression after EAC.} From a total of 235 participants, 66.4\% (60.0-72.4) of participants had viral load suppression after enhanced adherence counseling intervention. From all viral load suppressed participants, $53.2 \%$ were male and $46.1 \%$ were married. Majority (42.8\%) of viral load suppressed participants had primary educational status, and approximately $73 \%$ of viral load suppressed participants were at the efavirenz (EFV)based ART regimen. Almost half of viral load suppressed patients had 1000-5000 viral load copies/ $\mathrm{ml}$ at the start of EAC sessions, and $92 \%$ of viral load patients had good ART adherence level at baseline (Table 2).

\subsection{Factors Associated with Viral Load Suppression. On bi-} variate analysis gender, educational status, residence, baseline CD4 count, first viral load count, and baseline adherence level were significantly associated with viral load suppression. On multivariable analysis gender, educational status, duration on ART, and baseline viral load count greater than 1000 copies/ml were significant predictors of viral load suppression (Table 3 ).

Females were 1.2 times more likely to have viral load suppression as compared to male participants $(\mathrm{ARR}=1.2$, 95\% CI: 1.02-1.19). Primary or secondary and above educational status was associated with the risk of virologic suppression compared to those who cannot read and write $(\mathrm{ARR}=1.4,95 \% \mathrm{CI}: 1.03-1.84$, and $\mathrm{ARR}=1.7,95 \% \mathrm{CI}$ : 1.25-2.16, respectively). More than 12 months on ART was associated with decreased probability of suppression as compared to less than 12 months on ART (13-35 months, $\mathrm{ARR}=0.11,95 \% \mathrm{CI}: 0.03-0.38 ; 36-59$ months, $\mathrm{ARR}=0.35$, 95\% CI: 0.130-0.9491). But more than 60 months on ART was not significantly associated with viral load suppression. The probability of viral load suppression was $7 \%$ lower for participants who had 5001-10,000 copies/ml viral load count as compared to those who had 1000-5000 copies $/ \mathrm{ml}$ (ARR $=0.93,95 \%$ CI: 0.87-0.99). Similarly, the probability of viral load suppression was $56 \%$ lower for participants who had viral load count greater than 10,000 compared to those who had $1,000-5,000$ copies $/ \mathrm{ml} \quad(\mathrm{ARR}=0.44,95 \% \mathrm{CI}$ : 0.28-0.71) (Table 3).

3.4. Median Time to the Start of EAC Session after High Viral Load Detected. The median time to the start of the EAC sessions after high viral load ( $>1000$ copies $/ \mathrm{ml}$ ) detected date was 8 weeks (IQR 4-8 weeks). Significant number of participants $(78(33.2 \%))$ have started EAC sessions after $4-8$ weeks of high viral load detection and around 13\% of participants did not start the EAC sessions up to 3 months. The median time to take a second viral load test after complete enhanced adherence counseling session was 4 weeks (IQR 0-6 weeks). Half of the participants had a second viral load test within 2 weeks of completing the EAC session, but $28(12 \%)$ participants did not take the second viral load test for more than 8 weeks (Table 4 ).

\subsection{Time to Complete Enhanced Adherence Counseling} (EAC) Sessions. The median time to complete the EAC session was 17 weeks (IQR 10-33 weeks) (Figure 1) and differs by gender. It was 25 weeks in males and 13 weeks in females (Figure 2). Similarly, the median time to complete EAC was 13 weeks in urban and 26 weeks in rural. In this study, only $46.8 \%$ of participants have completed the EAC sessions within 3 months. Nearly one-third (27.2\%) of high viral load patients completed the EAC sessions after 6 months of initiation of counseling sessions (Table 4).

\section{Discussion}

This is one of the first studies in Ethiopia which assessed the outcome of the EAC program on HIV seropositive people with high viral load count. Our findings suggest that the overall viral load suppression after enhanced adherence counseling sessions was $66.4 \%(60.0-72.4)$. From all HIV seropositive with high viral load who were eligible for EAC, two-thirds of patients had viral load suppression (viral load less than 1000 copies $/ \mathrm{ml}$ ) after the EAC sessions conducted for 3-6 months. This re-suppression rate is near to the WHO target $(70 \%)$ [3]. But it is much higher than the viral suppression rates reported in Zimbabwe [16] and Uganda [11]. Most importantly, the current finding support WHO recommendations that suspected virologic failure (viral load count $>1,000$ copies/ $\mu \mathrm{l}$ at the first test) should be addressed by enhanced adherence counseling as well as repeat measurement before consideration of treatment switch to a second-line drug $[3,10]$. Thus, enhanced adherence counseling interventions can preserve the first-line treatment regimen. This could decrease health care costs and the transmission of resistant strains from the newly infected people.

In the current study, there is evidence on delay between ascertaining high viral load count (date of high viral load) and initiating EAC sessions. The result showed that onethird of individuals started the EAC session after 2 months of high viral load detected. This suggests the poor management of high viral load patients which might affect timely detection of treatment failure.

In this study, the EAC sessions were not completed within the recommended time. Of those with high viral loads, only $46.8 \%$ of participants completed their EAC session within the recommended time which is 12 weeks. This might be due to long travel distance to health facility because large proportion of participants in the current study were from rural residence. Previous studies also showed that long travel distance and lack of money for 
TABLE 1: Sociodemographic and clinical characteristics of high viral load HIV seropositive people from June 2016 and January 2019 , North Wollo Zone, Ethiopia.

\begin{tabular}{|c|c|c|c|}
\hline Variables & Category & Frequency & Percentage (\%) \\
\hline \multirow{5}{*}{ Age (years) } & $<10$ & 9 & 3.8 \\
\hline & $10-19$ & 29 & 12.4 \\
\hline & $20-29$ & 53 & 22.6 \\
\hline & $30-39$ & 60 & 25.5 \\
\hline & $\geq 40$ & 84 & 35.7 \\
\hline \multirow{3}{*}{ Sex } & Male & 114 & 48.5 \\
\hline & Female & 121 & 51.5 \\
\hline & Single & 65 & 27.7 \\
\hline \multirow{3}{*}{ Marital status } & Married & 109 & 46.4 \\
\hline & Widowed & 24 & 10.2 \\
\hline & Divorce & 37 & 15.7 \\
\hline \multirow{3}{*}{ Religion } & Orthodox & 166 & 70.6 \\
\hline & Muslim & 37 & 15.7 \\
\hline & Protestant & 32 & 13.7 \\
\hline \multirow{3}{*}{ Educational status } & Cannot read and write & 61 & 25.9 \\
\hline & Primary & 84 & 35.8 \\
\hline & Secondary and above & 90 & 38.3 \\
\hline \multirow{2}{*}{ Residence } & Urban & 132 & 56.2 \\
\hline & Rural & 103 & 43.8 \\
\hline \multirow{2}{*}{ Type of hospital } & General hospital & 157 & 66.8 \\
\hline & Primary hospital & 78 & 33.2 \\
\hline \multirow{3}{*}{ ART regimen } & NVP-based regimen & 63 & 26.8 \\
\hline & EFV-based regimen & 172 & 73.2 \\
\hline & $<12$ months & 60 & 25.5 \\
\hline \multirow{3}{*}{ Duration of ART } & 12-24 months & 48 & 20.4 \\
\hline & 25-59 months & 108 & 46.0 \\
\hline & $\geq 5$ years & 19 & 8.1 \\
\hline \multirow{3}{*}{ Adherence level } & Good & 195 & 83.0 \\
\hline & Fair & 10 & 4.3 \\
\hline & Poor & 30 & 12.8 \\
\hline \multirow{3}{*}{ WHO stage } & Stage 1 & 213 & 90.7 \\
\hline & Stage 2 or 3 & 22 & 9.3 \\
\hline & Working & 200 & 85.1 \\
\hline \multirow[t]{2}{*}{ Functional status } & Ambulatory & 30 & 12.8 \\
\hline & Bedridden & 5 & 2.1 \\
\hline \multirow{3}{*}{ Baseline CD4 } & $<200$ & 93 & 39.6 \\
\hline & $201-500$ & 42 & 17.9 \\
\hline & $\geq 500$ & 100 & 42.5 \\
\hline \multirow{2}{*}{ INH eligibility } & Yes & 165 & 70.2 \\
\hline & No & 70 & 29.8 \\
\hline \multirow{3}{*}{ Baseline viral load count } & $1,000-4,900$ & 105 & 44.7 \\
\hline & $5,000-10,000$ & 90 & 38.3 \\
\hline & $\geq 10,000$ & 40 & 17.0 \\
\hline
\end{tabular}

traveling to health institution affect ART adherence and follow-up visit within the recommended time $[17,18]$. Besides, the median time to complete the enhanced adherence counseling session was greater than 24 weeks in men, which is very far away from the suggested time $[3,10,12]$. This finding implies that some groups of people (men and rural) did not complete the counseling session within the accepted time range, which may lead to unnecessary delays in diagnosis of virologic failure (ARTresistance) and switch to the second-line ART regimen. Delaying ART switch for patients with resistance increases the risk of sexual transmission of ART-resistant strains [19-22], as well as the possibility of subsequent failure on second-line therapy in delays $[9,11,20,21]$. The healthcare provider must support rural community to complete the EAC session on time.

Being female was significantly associated with viral suppression. This could be due to the timely completion of their EAC session, which might have contributed to better adherence and response to ART therapy in women [20, 23-25]. Besides, in the current study, women had lower baseline viral load levels than men, which might contribute to better viral suppression. But the gender difference in viral suppression rate should be studied further.

Educational status was another factor which was independently associated with viral suppression. Those having primary education and above had high probability of viral load suppression when compared to those who cannot read 
TABLE 2: Results showing relationship between baseline characteristics and viral load re-suppression among study participants.

\begin{tabular}{|c|c|c|c|c|}
\hline \multirow{2}{*}{ Variables } & & \multicolumn{2}{|c|}{ Viral load } & \multirow{2}{*}{$p$ value } \\
\hline & & Suppressed $(n=156)(\%)$ & Nonsuppressed $(n=79)(\%)$ & \\
\hline \multirow{5}{*}{ Age } & $<10$ & $6(3.9)$ & $3(3.8)$ & \multirow{5}{*}{$\leq 0.001$} \\
\hline & $10-19$ & $26(16.7)$ & $3(3.8)$ & \\
\hline & $20-29$ & $28(18.0)$ & $25(31.7)$ & \\
\hline & $30-39$ & $32(20.4)$ & $28(35.4)$ & \\
\hline & $\geq 40$ & $64(41.0)$ & $20(25.3)$ & \\
\hline \multirow{2}{*}{ Sex } & Male & $63(53.2)$ & $51(51.8)$ & \multirow{2}{*}{$\leq 0.001$} \\
\hline & Female & $93(46.8)$ & $28(48.2)$ & \\
\hline \multirow{4}{*}{ Marital status } & Single & $45(29.6)$ & $20(24.1)$ & \multirow{4}{*}{0.120} \\
\hline & Married & $70(46.1)$ & $39(47.0)$ & \\
\hline & Widowed & $12(7.9)$ & $12(14.5)$ & \\
\hline & Divorce & $25(16.4)$ & $12(14.4)$ & \\
\hline \multirow{3}{*}{ Educational status } & Cannot read and write & $57(37.5)$ & $39(47.0)$ & \multirow{3}{*}{0.03} \\
\hline & Primary & $65(42.8)$ & $30(36.1)$ & \\
\hline & Secondary and above & $24(15.8)$ & $13(15.7)$ & \\
\hline \multirow{2}{*}{ Residence } & Urban & $65(42.8)$ & $34(41.0)$ & \multirow{2}{*}{$<0.001$} \\
\hline & Rural & $87(57.2)$ & $49(59.0)$ & \\
\hline \multirow{2}{*}{ Type of hospital } & General hospital & $103(67.8)$ & $54(65.1)$ & \multirow{2}{*}{0.412} \\
\hline & Primary hospital & $49(32.2)$ & $29(34.9)$ & \\
\hline \multirow{2}{*}{ ART regimen } & NVP-based regimen & $40(26.9)$ & $23(27.7)$ & \multirow{2}{*}{0.571} \\
\hline & EFV-based regimen & $111(73.1)$ & $57(72.3)$ & \\
\hline \multirow{4}{*}{ Duration of ART } & $\leq 12$ months & $42(26.9)$ & $18(22.8)$ & \multirow{4}{*}{0.037} \\
\hline & 13-35 months & $26(16.7)$ & $22(27.9)$ & \\
\hline & 36-59 months & $72(46.2)$ & $36(45.6)$ & \\
\hline & $\geq 60$ months & $16(10.3)$ & $3(3.8)$ & \\
\hline \multirow{3}{*}{ First viral load } & $1000-5000$ & $79(50.6)$ & $26(32.9)$ & \multirow{3}{*}{0.011} \\
\hline & $5001-10,000$ & $65(41.7)$ & $25(31.6)$ & \\
\hline & $\geq 10000$ & $12(7.7)$ & $28(35.4)$ & \\
\hline \multirow{3}{*}{ Baseline CD4 } & $<200$ & $53(34.0)$ & $40(50.6)$ & \multirow{3}{*}{0.641} \\
\hline & $201-500$ & $25(16.0)$ & $17(21.5)$ & \\
\hline & $\geq 500$ & $78(50.0)$ & $22(27.9)$ & \\
\hline \multirow{3}{*}{ Adherence level } & Good & $139(91.5)$ & $56(67.5)$ & \multirow{3}{*}{0.210} \\
\hline & Fair & $3(2.0)$ & $7(8.4)$ & \\
\hline & Poor & $10(6.5)$ & $20(24.1)$ & \\
\hline \multirow{2}{*}{ WHO stage } & Stage 1 & $139(91.5)$ & $74(89.2)$ & \multirow[b]{2}{*}{0.012} \\
\hline & Stage 2 or 3 & $13(8.6)$ & $7(8.4)$ & \\
\hline
\end{tabular}

$\mathrm{ART}=$ antiretroviral therapy; $\mathrm{EFV}=$ efavirenz; NVP=nevirapine; $\mathrm{WHO}=$ World Health Organization.

and write. This is consistent with what has been found in previous evidence, which showed that there was a significant difference in viral suppression rate among different educational levels (67\% in incomplete primary education versus $82-87 \%$ in individuals with primary education and above) [26]. This could be due to that educated people typically engage in healthier behaviors including ART drug adherence and better understand information during enhanced adherence counseling session [27].

Duration on ART was significantly associated with viral load suppression. Patients who have taken ART for about 13-59 months were less likely to have viral suppression compared to those who have taken ART drug for less than 12 months. This could be associated with destruction of CD4 cells over time. An individual who had greater than or equal to 5,000 copies/ml initial viral load levels were less likely to develop viral load suppression. This finding is supported by previous studies which showed that initial viral load levels may be a good determinant of viral load suppression in patients with high viral load $[16,28]$.
The major strength of the study was inclusion of all public hospitals in North Wollo Zone and inclusion of all high viral load patients for the last 2 years. The data were collected from the patient chart, follow-up chart, and high viral load registration books, which are the primary level of documentation of the patient information in the country. The key weakness of this study is that data were collected by documentary review, and hence, the analysis and interpretation of the data are restricted to only those variables that are captured in the patient records. Some of the important variables, such as wealth index, distance to health institutions, and substance use, which could have played a major role in initial viral load testing, enrolment for EAC, repeat viral load testing, and viral suppression, were not accessible. In this study, there could have been selection bias arising from the fact that the samples with recorded second viral load could have been obtained from individuals who had regular follow-up or that patients who did not have regular follow-up/drop out patients could have been more likely to be nonsuppressed. 
TABLE 3: Baseline demographic and clinical characteristics associated with viral load suppression among high viral load HIV infected people after enhanced adherence counselling (EAC) session between June 2016 and January 2019, Ethiopia.

\begin{tabular}{|c|c|c|c|c|}
\hline Variables & Category & CRR (95\% CI) & ARR $(95 \% \mathrm{CI})$ & $p$ value \\
\hline Sex & $\begin{array}{l}\text { Male } \\
\text { Female }\end{array}$ & $\begin{array}{c}1 \\
1.39(1.148-1.685)^{*}\end{array}$ & $\begin{array}{c}1 \\
1.18(1.017-1.192)\end{array}$ & $<0.001$ \\
\hline Educational status & $\begin{array}{c}\text { Cannot read and write } \\
\text { Primary } \\
\text { Secondary and above }\end{array}$ & $\begin{array}{c}1 \\
1.62(1.171-2.241)^{*} \\
1.87(1.378-2.556)^{*}\end{array}$ & $\begin{array}{l}1.38(1.032-1.841) \\
1.65(1.253-2.164)\end{array}$ & $\begin{array}{c}0.030 \\
<0.001\end{array}$ \\
\hline Residence & $\begin{array}{l}\text { Urban } \\
\text { Rural }\end{array}$ & $\begin{array}{c}1 \\
0.59(0.472-0.730)^{*}\end{array}$ & $\begin{array}{c}1 \\
0.66(0.544-1.805)\end{array}$ & 0.301 \\
\hline Duration of ART & $\begin{array}{c}\leq 12 \text { months } \\
13-35 \text { months } \\
36-59 \text { months } \\
\geq 60 \text { months }\end{array}$ & $\begin{array}{c}1 \\
0.77(0.568-1.053) \\
0.95(0.770-1.178) \\
1.20(0.932-1.553)\end{array}$ & $\begin{array}{c}1 \\
0.11(0.031-0.379) \\
0.35(0.130-0.949) \\
0.40(0.738-2.217)\end{array}$ & $\begin{array}{l}0.014 \\
0.023 \\
0.147\end{array}$ \\
\hline First viral load & $\begin{array}{c}1000-5000 \\
5001-10,000 \\
\geq 10000\end{array}$ & $\begin{array}{c}1 \\
0.96(0.811-1.136) \\
0.40(0.245-0.648)^{*} \\
\end{array}$ & $\begin{array}{c}1 \\
0.93(0.871-0.989) \\
0.44(0.277-0.701) \\
\end{array}$ & $\begin{array}{c}0.021 \\
<0.001 \\
\end{array}$ \\
\hline Baseline CD4 & $\begin{array}{c}<200 \\
201-500 \\
\geq 500\end{array}$ & $\begin{array}{c}1 \\
1.04(0.769-1.418) \\
1.37(1.115-1.680)^{*}\end{array}$ & $\begin{array}{c}1 \\
0.98(0.985-1.986) \\
0.83(0.467-1.387) \\
\end{array}$ & $\begin{array}{l}0.101 \\
0.081\end{array}$ \\
\hline Adherence level & $\begin{array}{l}\text { Good } \\
\text { Fair } \\
\text { Poor }\end{array}$ & $\begin{array}{c}1 \\
0.08(0.012-0.521)^{*} \\
0.18(0.060-0.531)^{*}\end{array}$ & $\begin{array}{l}0.12(0.092-1.021) \\
0.54(0.240-1.124)\end{array}$ & $\begin{array}{l}0.215 \\
0.131\end{array}$ \\
\hline WHO stage & $\begin{array}{c}\text { Stage } 1 \\
\text { Stage } 2 \text { or } 3\end{array}$ & $\begin{array}{c}1 \\
1.03(0.762-1.392)\end{array}$ & $\begin{array}{c}1 \\
1.20(0.845-1.352)\end{array}$ & $\begin{array}{c}1 \\
0.801\end{array}$ \\
\hline
\end{tabular}

$\mathrm{CRR}=$ crude risk ratio; $\mathrm{ARR}=$ adjusted risk ratio; $\mathrm{ART}=$ antiretroviral therapy; $\mathrm{WHO}=$ World Health Organization. ${ }^{*}=p<0.05$.

TABle 4: Time from high viral detected to EAC session start and time from EAC complete to repeated viral load.

\begin{tabular}{|c|c|c|c|}
\hline Category & Subcategory & Frequency & Percentage \\
\hline \multirow{6}{*}{ Time from high viral load detected to EAC session start } & Median (IQR) & 8 (4-10 weeks) & - \\
\hline & $<2$ weeks & 36 & 15.3 \\
\hline & 2-4 weeks & 35 & 14.9 \\
\hline & $4-8$ weeks & 78 & 33.2 \\
\hline & $8-12$ weeks & 56 & 23.8 \\
\hline & $\geq 12$ weeks & 30 & 12.8 \\
\hline \multirow{3}{*}{ Time to complete EAC sessions } & $\geq 12$ weeks & 110 & 46.8 \\
\hline & 13-24 weeks & 61 & 26.0 \\
\hline & $\geq 25$ weeks & 64 & 27.2 \\
\hline \multirow{6}{*}{ Time from EAC session complete to repeat viral load } & Median (IQR) & 4 (0-6 weeks) & - \\
\hline & $<2$ week & 117 & 49.8 \\
\hline & 2-4 weeks & 51 & 21.7 \\
\hline & $4-8$ weeks & 39 & 16.6 \\
\hline & $8-12$ weeks & 10 & 4.3 \\
\hline & $\geq 12$ weeks & 18 & 7.7 \\
\hline
\end{tabular}

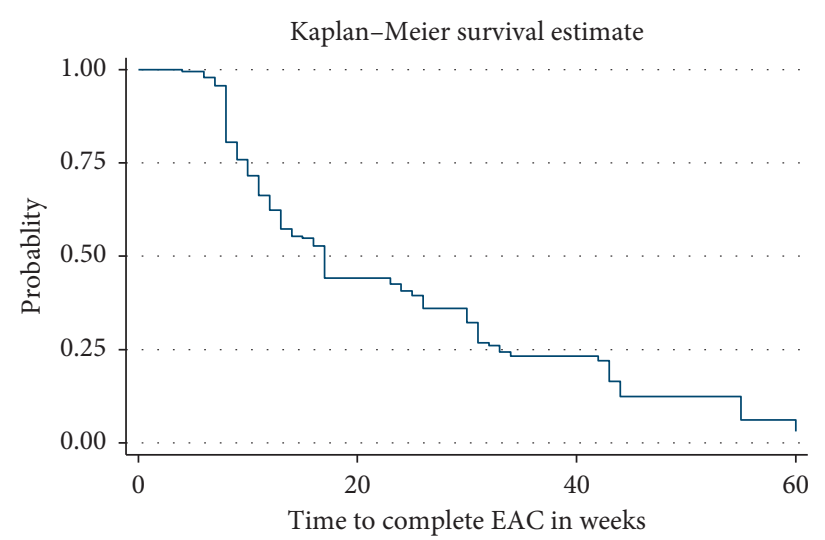

FIGURE 1: Kaplan-Meier survival curves showing failure experiences of patients who completed EAC. 


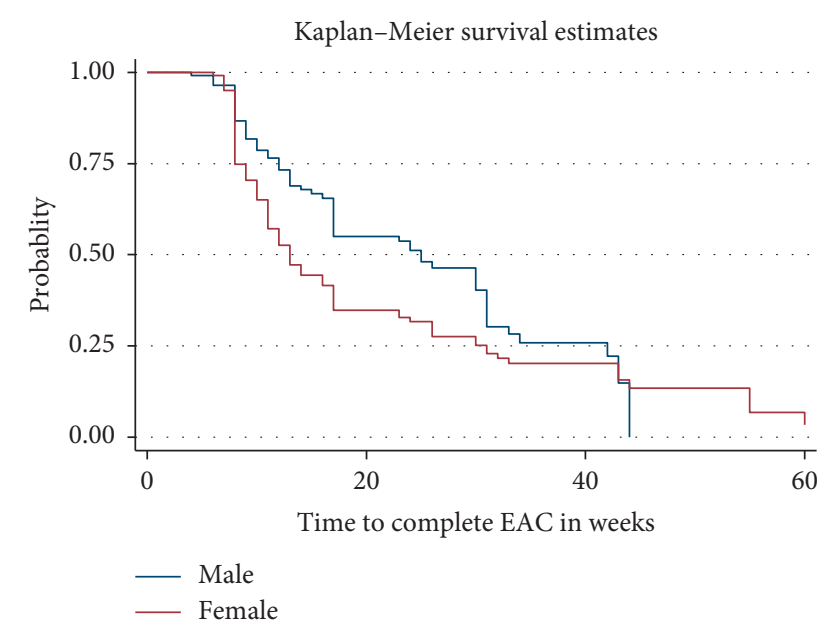

Figure 2: Kaplan-Meier survival curves showing failure experiences of patients who completed EAC by sex.

\section{Conclusion}

In this study, about $66.4 \%$ of the patients had viral load suppression at 3 months or later. The factors that were statistically associated with viral load suppression on repeat testing at 3 or more months were gender, educational status, duration on ART, and initial viral load count. Results highlight the importance of education in viral load suppression rate. The study shows gaps in time to enrolment into EAC and repeat viral load testing after complete EAC. The explanations for these gaps need to be assessed in future research studies.

\section{Abbreviations}

AIDS: Acquired immunodeficiency syndrome

ART: Antiretroviral therapy

BMI: Body mass index

EAC: Enhanced adherence counseling

HIV: Human immunodeficiency virus

VL: $\quad$ Viral load

WHO: World Health Organization.

\section{Data Availability}

The dataset used and analyzed for the study is available from the corresponding author upon reasonable request (gedefawdiress@gmail.com).

\section{Ethical Approval}

Ethical clearance was obtained from the Institutional Review Committee of Woldia University. Since it was a retrospective analysis of the identified data, a waiver of consent was obtained. Even though most of the data were collected from the patient chart and follow-up card, a written patient consent form without any personal identifiers was prepared. The recorded data were not accessed by a third person except by the principal investigator and kept confidentially.

\section{Conflicts of Interest}

The authors declare that they have no conflicts of interests.

\section{Authors' Contributions}

GD conceived the presented idea, drafted the manuscript, and analyzed the data. SD drafted the manuscript. BA read and approved the final manuscript. SA and $\mathrm{AD}$ discussed the results and commented on the manuscript. All authors read and approved the final manuscript.

\section{Acknowledgments}

The authors wish to thank the academic staff of Woldia University, Faculty of Health Science, for suggestion and selection of topic. The authors would also like to thank Woldia University for giving the chance to conduct this study. This work was supported by Woldia University.

\section{References}

[1] WHO, Global Update on HIV, World Health Organisation, Geneva, Switzerland, 2017.

[2] WHO, Consolidated Guidelines on the Use of Antiretroviral Drugs for Treating and Preventing HIV Infection, World Health Organisation, Geneva, Switzerland, 2013.

[3] 90-90-90, An Ambitious Treatment Target to Help End the AIDS Epidemic, UNAIDS, Geneva, Switzerland, 2017, https:// www.unaids.org/sites/default/files/media_asset/90-90-90_en. pdf.

[4] G. Bernabas, K. Emanuel, and Y. Berhane, "Antiretroviral therapy program in Ethiopia benefits from virology treatment monitoring," Ethiopian Journal of Health Sciences, vol. 27, no. 1, pp. 3-5, 2017.

[5] WHO Consolidated, Guidelines on the Use of Antiretroviral Drugs for Treating and Preventing HIV Infection, Recommendations for a Public Health Approach, Geneva,Switzerland, 2014.

[6] K. Brooks, L. Diero, A. DeLong et al., "Treatment failure and drug resistance in HIV-positive patients on tenofovir-based first-line antiretroviral therapy in western Kenya," Journal of the International AIDS Society, vol. 19, no. 1, p. 20798, 2016.

[7] D. Haile, A. Takele, K. Gashaw, H. Demelash, and D. Nigatu, "Predictors of treatment failure among adult antiretroviral treatment (ART) clients in Bale zone hospitals, South Eastern Ethiopia," PLoS One, vol. 11, no. 10, Article ID e0164299, 2016.

[8] N. F. Telele, A. W. Kalu, G. Marrone et al., "Baseline predictors of antiretroviral treatment failure and lost to follow up in a multicenter countrywide HIV-1 cohort study in Ethiopia," PLoS One, vol. 13, no. 7, Article ID e0200505, 2018.

[9] WHO, Adapting and Implementing New Recommendaation on HIV Patient Monitoring, World Health Organisation, Geneva, Switzerland, 2017.

[10] Ministry of Health, National Guidelines for Comprehensive HIV Prevention Care and Treatment, Ministry of Health, Ethiopia, 2017.

[11] E. Nasuuna, J. Kigozi, L. Babirye, A. Muganzi, N. K. Sewankambo, and D. Nakanjako, "Low HIV viral suppression rates following the intensive adherence counseling (IAC) program for children and adolescents with viral failure in public health facilities in Uganda," BMC Public Health, vol. 18, no. 1, p. 1048, 2018. 
[12] R. V. Barnabas, P. Revill, N. Tan, and A. Phillips, "Cost-effectiveness of routine viral load monitoring in low- and middle-income countries: a systematic review," Journal of the International AIDS Sociey, vol. 20, 2017.

[13] North Wollo Zonal Health Department, 2018.

[14] Human Resource Departement of Woldia General Hospital.

[15] Ethipian Federal Ministry of Health, "National consolidated guidelines for comprehensive hiv prevention," Care And Treatment, 2018, https://www.afro.who.int/sites/default/files/ 2019-04/National_Comprehensive_HIV_Care_20Guideline_ 2018.pdf.

[16] T. Bvochora, S. Satyanarayana, K. C. Takarinda et al., "Enhanced adherence counselling and viral load suppression in HIV seropositive patients with an initial high viral load in Harare, Zimbabwe: operational issues," PLoS ONE, vol. 14, no. 2, pp. 3-8, 2019.

[17] I. N. Azia, F. C. Mukumbang, and B. vW, "Barriers to adherence to antiretroviral treatment in a regional hospital in Vredenburg, Western Cape, South Africa," Southern African Journal of HIV Medicine, vol. 17, no. 1, 2016.

[18] F. C. Mukumbang, J. C. Mwale, and B. van Wyk, "Conceptualising the factors affecting retention in care of patients on antiretroviral treatment in Kabwe District, Zambia, using the ecological framework," AIDS Research and Treatment, vol. 2017, p. 11, 2017.

[19] C. Celum and R. Barnabas, "Reaching the 90-90-90 target: lessons from HIV self-testing," The Lancet HIV, vol. 6, no. 2, pp. e68-e69, 2019.

[20] G. G. Hailu, D. G. Hagos, A. K. Hagos, A. G. Wasihun, and T. A. Dejene, "Virological and immunological failure of HAART and associated risk factors among adults and adolescents in the Tigray region of Northern Ethiopia," PLoS One, vol. 13, no. 5, Article ID e0196259, 2018.

[21] M. C. Hosseinipour, J. J. van Oosterhout, R. Weigel et al., "The public health approach to identify antiretroviral therapy failure: high-level nucleoside reverse transcriptase inhibitor resistance among Malawians failing first-line antiretroviral therapy," AIDS (London, England), vol. 23, no. 9, pp. 11291131, 2009.

[22] N. Kumarasamy, V. Madhavan, K. K. Venkatesh et al., "High frequency of clinically significant mutations after first-line generic highly active antiretroviral therapy failure: implications for second-line options in resource-limited settings," Clinical Infectious Diseases, vol. 49, no. 2, pp. 307-308, 2009.

[23] A. M. Geretti, C. Smith, A. Haberl et al., "Determinants of virological failure after successful viral load suppression in first-line highly active antiretroviral therapy," Antiviral Therapy, vol. 13, no. 7, pp. 927-936, 2008.

[24] K. Peltzer, N. Friend-du Preez, S. Ramlagan, and J. Anderson, "Antiretroviral treatment adherence among HIV patients in KwaZulu-Natal, South Africa," BMC Public Health, vol. 10, p. 111, 2010.

[25] W. M. Bezabhe, L. Chalmers, L. R. Bereznicki, G. M. Peterson, M. A. Bimirew, and D. M. Kassie, "Barriers and facilitators of adherence to antiretroviral drug therapy and retention in care among adult HIV-positive patients: a qualitative study from Ethiopia," PLoS One, vol. 9, no. 5, Article ID e97353, 2014.

[26] J. Del Amo, "Inequalities by educational level in response to combination antiretroviral treatment and survival in HIVpositive men and women in Europe (1996-2013): a collaborative cohort study," AIDS, 2016.

[27] M. John and C. Ross, Education, Social Status, and Health (Social Institutions and Social Change Series) 1st Edition,
2003, https://www.amazon.com/Education-Social-StatusHealth-Institutions/dp/0202307077.

[28] M. S. F. Making, Viral Load Routine: Successes and Challenges in the Implementation of Routine HIV Viral Load Monitoring, Médecins sans Frontiéres (MSF), Geneva, Switzerland, 2016, https://www.msf.org/sites/msf.org/files/making_viral_load_ routine_part_1_programmatic_strategies.pdf. 